\title{
- Evaluation and improvement of empirical models of global solar irradiation: case study northern Spain
}

\author{
F. Antonanzas-Torres ${ }^{\text {a,* }}$, A. Sanz-Garcia a , F. J. Martínez-de-Pisón-Ascacíbara, \\ O. Perpiñán-Lamigueiro ${ }^{\mathrm{b}, \mathrm{c}}$ \\ ${ }^{a}$ EDMANS Group, Department of Mechanical Engineering, University of La Rioja, Logroño, Spain. \\ ${ }^{b}$ Electrical Engineering Department, EUITI-UPM, Ronda de Valencia 3, 28012 Madrid, Spain. \\ ${ }^{c}$ Instituto de Energía Solar, Ciudad Universitaria s/ $n$, Madrid, Spain
}

\section{\& Abstract}

This paper presents a new methodology to build parametric models to estimate global solar irradiation adjusted to specific on-site characteristics based on the evaluation of variable importance. Thus, those variables higly correlated to solar irradiation on a site are implemented in the model and therefore, different models might be proposed under different climates. This methodology is applied in a study case in La Rioja region (northern Spain). A new model is proposed and evaluated on stability and accuracy against a review of twenty-two already existing parametric models based on temperatures and rainfall in seventeen meteorological stations in La Rioja. The methodology of model evaluation is based on bootstrapping, which leads to achieve a high level of confidence in model calibration and validation from short time series (in this case five years, from 2007 to 2011).

The model proposed improves the estimates of the other twenty-two models with average mean absolute error (MAE) of $2.195 \mathrm{MJ} / \mathrm{m}^{2}$ day and average confidence interval width $(95 \%$ C.I., $\mathrm{n}=100$ ) of $0.261 \mathrm{MJ} / \mathrm{m}^{2}$ day. $41.65 \%$ of the daily residuals in the case of SIAR and $20.12 \%$ in that of SOS Rioja fall within the uncertainty tolerance of the pyranometers of the two networks (10\% and 5\%, respectively). Relative differences between measured and estimated irradiation on an annual cumulative basis are below $4.82 \%$. Thus, the proposed model might be useful to estimate annual sums of global solar irradiation, reaching insignificant differences between measurements from pyranometers.

Keywords: Solar global irradiation, empirical models, time series, evapotranspiration

\section{Nomenclature}

$B C$ Bristow \& Campbell model

$\Delta T$ Daily range of maximum and minimum temperatures

$\overline{\Delta T_{\mathcal{C}}}$ Average $\Delta T$ of the calibration dataset

$\Delta T_{i-1}$ Daily range of maximum and minimum temperatures on day $i-1$

$\Delta T_{m}$ Monthly average of $\Delta T$

$\overline{\Delta T_{t}}$ Average $\Delta T$ of the testing dataset

$h$ Elevation above sea level

\footnotetext{
*Corresponding author

Email address: antonanzas. fernando@gmail . com (F. Antonanzas-Torres)
}

Preprint submitted to Renewable Energy 
36 $H$ Daily mean relative humidity

${ }_{37} J$ Julian day

38 $M$ Logical variable of rainfall

39 $M A E_{\text {tes }}$ Mean absolute error of testing

40 $M A E_{\text {val }}$ Mean absolute error of validation

${ }_{41} \overline{M A E_{\text {val }}}$ Average $M A E_{\text {val }}$ for the whole set of stations

$42 \quad n$ Length in days of the validation database

${ }_{43} \quad P$ Rainfall

${ }_{44} \quad P_{c}$ Yearly average rainfall in $\mathrm{mm}$ for the calibration dataset

${ }_{45} \quad P_{t}$ Yearly rainfall in $\mathrm{mm}$ for the testing dataset

${ }_{46} p_{\text {sat }}\left[T_{\text {max }}\right]$ Vapor saturation pressure at $T_{\max }$

$47 \quad R^{2}$ Coefficient of determination

${ }_{48} \quad R_{a}$ Extraterrestrial irradiation

$49 \quad R_{a, i-30}$ Extraterrestrial irradiation on day $i-30$

so $\quad R_{S}$ Daily global solar irradiation

${ }_{51} \overline{R_{S}}$ Monthly mean of daily global irradiation

$52 \quad \overline{R_{S, c}}$ Average $R_{S}$ for the calibration period

${ }_{53} \quad R_{s, \text { est }}$ Daily estimated irradiation

${ }_{54} R_{s, \text { meas }}$ Daily measured irradiation

${ }_{55} \overline{R_{s, t}}$ Average $R_{S}$ for the testing period

${ }_{56} \overline{R_{M A E, v a l}}$ Average confidence interval width of MAE

$57 \overline{R_{R M S E, v a l}}$ Average confidence interval width of RMSE

${ }_{58} \overline{R_{M S E_{v a l}}}$ Average $R M S E_{\text {val }}$ for the whole set of stations

59 $R M S E_{\text {tes }}$ Root mean square error of testing

60 $T_{\text {avg }}$ Daily average air temperature

${ }_{61} T_{\max }$ Daily maximum temperature

${ }_{62} T_{\min }$ Daily minimum temperature

${ }_{63} \theta$ Julian angle

${ }_{64} W$ Daily mean wind speed 


\section{Introduction}

Solar irradiation research is a field of rising interest due to its many applications, such as the study of evapotranspiration [1] and optimization of water demand in irrigation, crop forecasting [2] from near-to-present measurements and estimates, the development and reduction of uncertainties in solar energy technologies (generation and internal rate of return) [3], the adjustment of energy policies to promote solar energies, and research on climate change [4]. The high cost of measuring solar irradiation with pyranometers and the scarcity of long, reliable datasets for specific locations has propitiated the progress in estimators such as the analysis of satellite images [4,5], artificial neural networks (ANN) [6, 7] and empirically-based parametric models [8-10]; the latter estimating daily global horizontal irradiation $\left(R_{S}\right)$ from other meteorological variables.

Satellite-based $R_{S}$ estimates are only provided with high resolution for specific areas in the planet, for example, 70S-70N, 70W-70E in the Satellite Application Facility for Climate Monitoring (CM SAF) [11], Helioclim1 and Helioclim3 from SODA [12]. In other areas, resolution from satellite-based estimates is low, such as in some regions of South America and South-East Asia (INPE [13] and the National Renewable Energy Laboratory (NREL) [14] with 40x40km resolution). The NASA Surface meteorology and Solar Energy (SSE) [15] coverage is global but resolution is very low $\left(1 \times 1^{\circ}\right)$. Due to the effect of local microclimatic events on $R_{S}$, daily and annual divergence within a $40 \times 40 \mathrm{~km}$ or $1^{\circ} \times 1^{\circ}$ cell might be significant [16]. In addition, satellitebased daily estimates are not generally freely accesible in the near present. For instance, the SODA provides $R_{S}$ from Helioclim 1 for the period 1985-2005, Helioclim 3 for the year 2005 and from the SSE database for the period 1983-2005. These near-to-present estimates are necessary in different applications such as the estimation of evapotranspiration of previous days to forecast irrigation. As a result, the empirically-based parametric models stand out because of their high simplicity in estimating near-to-present $R_{S}$ from measurements of commonly registered variables, generally registered with a higher distribution than the satellite resolution.

[17] and [18] developed the first parametric models to estimate $R_{S}$ out of sunshine records and introduced the concept of the atmospheric transmittance that affects incoming extraterrestrial irradiation $\left(R_{a}\right)$. The common figure of most parametric models is that they account for latitude, solar declination, the Julian day $(J)$, and day length by including $R_{a}$ [19]. [20] included mean daily cloud coverage to explain $R_{s}$. [21] introduced relative humidity and maximum temperature to estimate the monthly mean of the daily irradiation $\left(\overline{R_{S}}\right)$. However, the scarcity of sunshine and cloud cover records limits the usage of these methods to the location of validation.

[9], [22], and [8] developed the first models in which $R_{S}$ is estimated through the daily range of maximum and minimum temperatures $(\Delta T)$. Note that in these models $\Delta T$ behaves as an indicator of atmospheric transmittance, providing information about cloud cover. The higher emissivity of clouds than clear sky makes the maximum air temperature decrease and the minimum temperature increase, and as a result the $\Delta T$ decreases [23].

[24] studied the [9] model with $\overline{R_{s}}$, distinguishing between inland and coastal locations and obtaining higher accuracy in monthly than in daily estimates [25]. Other authors also modified the [9] model, introducing elevation [26], or modifying the square root by a Neperian logarithm [27] (the latter attributing it to [25]).

Rainfall $(P)$ was introduced as an explanatory variable directly $[10,28]$ or as a binary variable $(M)$ equal to 1 in days with some rainfall (denoted as rainy days) and 0 in days without any rainfall recorded (non-rainy days) [29-31]. According to previous papers, [30,31] rejected using $\Delta T$ in his model, considering $P$ sufficient to explain $R_{s}$. [30] also rejected $R_{a}$ and applied Fourier series based on the julian angle $(\theta)$, corresponding to the angle in radians of the $J$.

[8] (hereinafter $B C$ ) calculated $\Delta T$ as the difference between the maximum temperature of 
the day and the average of the minimum temperatures of the current day and the following day. [32] modified the $B C$ model, calculating $\Delta T$ related to rainfall. [19] studied the influence of $\Delta T$ on estimations, calculated as the difference between the maximum $\left(T_{\max }\right)$ and minimum temperatures $\left(T_{\min }\right)$ and as $\Delta \mathrm{T}$ as per $B C$ and evaluated it with sixteen $B C$ and [9] derived models. Eventually, better estimations were achieved with $\Delta T$ as the difference between $T_{\max }$ and $T_{\min }$. The $B C$ equation has also been modified by considering some parameters as constants $[1,19,33,34]$. The last of this papers attributed two new models to [33] and [35]. Additionally, [33] concluded that [25] and $B C$ models perform better for $\overline{R_{s}}$ than for daily values. [36] and latter [35] (who referred it as $B C$ ) included the monthly mean of the daily $\Delta T$ to smooth the results of the $B C$ model. [36] also developed a model in which the daily average temperature was introduced. [37, 38] also modified the $B C$ model, introducing the $R_{a}$ as a function of the atmospheric transmittance. Indeed, several papers have proved the efficacy of the $B C$ model by comparing it with their own models or with other models, e.g. [1, 19, 23, 28, 29, 32-35, 39-42].

Most of parametric models to estimate $R_{s}$ have been derived from the [9] and the $B C$ models by adding other variables that were proved to achieve better estimates where validated. However, a variable which might be correlated with $R_{S}$ in a site, might not have such a dependency in other site [26]. This paper proposes the evaluation of variable importance as a method to adjust general models, i.e., the $B C$ model. New models are then built by including important variables, obtained by on-site specific relationships between predictors and $R_{S}$.

Several papers have already evaluated models according to test errors, assessing the capacity of generalization under unproven data [23, 35, 39]. Nevertheless, models might generate low test errors for a specific time series while still being unstable under slight variations in the calibration data [43]. This paper also proposes an evaluation including stability and accuracy under different initial conditions as model selection criteria, and implements it on twenty-four parametric models (including two new models built on the method of evaluation of variable importance) in seventeen meteorological stations in La Rioja (Spain). The estimates of the best performing model are also compared with the CMSAF SIS satellite-derived database.

Table 1 summarizes the twenty-four models studied.

\section{Meteorological data}

The assessment is performed in La Rioja, a $5028 \mathrm{~km}^{2}$ region of Spain with significant climatic differences mainly due to differences in elevation and the smoothing influence of the Ebro River. The daily meteorological data is provided by two public agencies, SOS Rioja [44] and SIAR (Service of Agroclimatic Information of La Rioja) [45], with records taken every fifteen and thirty minutes respectively. $R_{S}$ is measured by SOS Rioja with Geonica sensors CM-6B and $E Q 08$, which are classed as First Class pyranometers according to the ISO9060 and by SIAR with Kipp\&Zonen CM3 and Hukseflux LP02, which are Second Class pyranometers with 5\% and 10\% daily tolerance levels respectively. The impact of the horizon effect on $R_{S}$ has been analyzed and not taken into account, since sky-view factors (ratio of visible sky related to the potential visible sky) are between 0.985-0.999, substantially lower than the uncertainty of sensors and models and therefore negligible. $T_{\max }, T_{\min }$ and $P$ are recorded with tolerances of $0.1^{\circ} \mathrm{C}$ and $0.1 \mathrm{~mm}$ by SOS Rioja and $0.2^{\circ} \mathrm{C}$ and $0.2 \mathrm{~mm}$ by SIAR. Additionally, average wind speed $(W)$ and relative humidity $(H)$ are recorded with $0.3 \frac{\mathrm{m}}{\mathrm{s}}$ and $3 \%$ tolerance respectively. Eventually, a total number of seventeen meteorological stations are selected (see Figure 1), with five complete years of daily historical data on the aforesaid variables from 2007 to 2011. Spurious data are filtered out according to the following limits, $T_{\max }$ lower than $45^{\circ} \mathrm{C}, T_{\min }$ higher than $-20^{\circ} \mathrm{C}$, irradiance lower than $1150 \frac{\mathrm{W}}{\mathrm{m}^{2}}, R_{s}$ lower than the daily $R_{a}, P$ lower than $40 \frac{\mathrm{mm}}{\mathrm{h}}, W$ lower than $30 \frac{\mathrm{m}}{\mathrm{s}}$ and $H$ 
lower than $100 \%$. Spurious data account for less than $0.14 \%$ and are replaced by the average of the previous and following measurements.

The time series of daily values from 2007 to 2011 of each station is divided into the calibration dataset, running from 2007 to 2010 and the testing dataset, which covers 2011 alone. Table 2 provides general information about the main variables measured during the calibration and testing periods.

Additionally, $R_{S}$ from the CM SAF SIS for 2007-2011 is obtained to evaluate and compare errors from the best-performing parametric model with those from this satellite-derived database.

\section{Method}

\subsection{Methodology of model evaluation}

The analysis of robustness proposed leads to the stability of models being assessed under many different initial conditions, and it is advisable to select the most suitable model, based not only on the lowest testing errors [46]. The evaluation is based on bootstrapping to extract a large amount of knowledge from a short time series [47, 48]. It is performed with each model at each station. $80 \%$ of the calibration dataset for every station (1168 days) is sampled to calibrate the parameters of each model. The remaining 20\% (292 days) is used to validate the calibration by calculating the validation mean absolute error $\left(M A E_{v a l}\right)$ and the validation root mean square error $\left(R M S E_{v a l}\right)$. This process is repeated one hundred times, resampling the $80 \%$ of the calibration dataset and calculating $M A E_{v a l}$ and $R M S E_{v a l}$ to eventually obtain the confidence intervals of the model parameters and errors.

$$
\begin{aligned}
M A E_{\text {val }} & =\frac{1}{n} \sum_{i=1}^{n}\left|\left(R_{s, \text { meas }}-R_{s, e s t}\right)\right| \\
R M S E_{\text {val }} & =\sqrt{\frac{1}{n} \sum_{i=1}^{n}\left(R_{s, \text { meas }}-R_{s, \text { sst }}\right)^{2}}
\end{aligned}
$$

Where, $R_{s, \text { meas }}$ and $R_{s, e s t}$ stand for daily measured irradiation and daily estimated irradiation with the model to be validated. $n$ stands for the length in days of the validation database (292 days).

Each model is calibrated with both spectral projected gradient methods for large-scale optimization [49] and a quasi-Newton algorithm known as the Broyden, Fletcher, Goldfarb and Shanno (BFGS) method [50], which updates an approximation to the inverse Hessian along with a point line search strategy [51]. The parameters calibrated minimize the sum of the square residuals between the measurements $\left(R_{s, \text { meas }}\right)$ and the estimations $\left(R_{s, e s t}\right)$. A combination of square errors in model calibration, and mean absolute errors $(M A E)$ is chosen as indicators of model performance to reduce the impact of outliers in the evaluation [52].

The stability and accuracy of each model are assessed at the set of stations as a whole with the mean confidence interval width of MAE $\left(\overline{R_{M A E, v a l}}\right)$ and the mean MAE $\left(\overline{M A E_{v a l}}\right)$. The unpaired $t$ - test is also evaluated to determine if $M A E_{v a l}$ means are statistically different between pairs of models within each station. The $t$ is calculated with Equation 3 and then the $p-v a l u e$ of the null hypothesis is derived.

$$
t=\frac{\overline{x_{i}}-\overline{x_{j}}}{\sqrt{\frac{s^{2}{ }^{2}-s^{2} j}{n}}}
$$

where $\overline{x_{i}}$ and $\overline{x_{j}}$ are the mean $M A E_{v a l}$ by bootstrapping with 100 samples of model $i$ and $j, s_{i}$ and $s_{j}$ the standard deviations and $n$ the number of samples. 
The capacity of generalization for non-common values is assessed with the confidence interval width of RMSE $\left(\overline{R_{R M S E, v a l}}\right)$ and the mean RMSE $\left(\overline{R M S E_{v a l}}\right)$, as a result of the amplifying property of this statistic with outliers.

The capability for generalization under unproven continuous data [53] is assessed within the testing dataset with the testing MAE (MAE tes $)$. The figures for the model parameters are obtained from the median of the bootstrapping distributions.

The analysis described in this paper has been implemented using the free software environment R [54] and several contributed packages: gstat [55] and sp [56] for the geostatistical analysis, optimx [57] for the calibration of models, solaR [58] for the solar geometry, raster [59] for spatial data manipulation and analysis, and rasterVis [60] for spatial data visualization methods.

\subsection{Methodology of model development}

The evaluation of variable importance leads to improve the performance of a general model with specific relationships between predictors and outcomes of the site to be assessed. This evaluation is performed by means of a loess smoother fit model, also known as locally weighted polynomial regression, which is fitted between the outcome and the predictors [61]. Each point $(x)$ of the dataset is fitted with a low-degree polynomial. The polynomial is adjusted with weighted least squares, giving more weight to points near the point whose response is being estimated and less weight to points further away. The weights are determined by their distance from $x$ with the tricubic weight function (Equation 3).

$$
\omega(x)=\left(1-\left|x^{3}\right|\right)
$$

Eventually, the $R^{2}$ is calculated for this model against the intercept only null model. The $R^{2}$ is returned as a relative measure of variable importance.

The evaluation is performed with typically used variables such as $P, M$ and $\Delta T$ and other two non-commonly used variables $W$ and $H$ of the study day $(i)$ and of three days, two days and the day before $(i-3, i-2, i-1)$ and after $(i+3, i+2, i+1)$. Those variables with high $R^{2}$ are useful to improve the estimation of $R_{S}$ within a classic model, such as the $B C$. As a result, new $B C$-derived models are built according to Equations $5 \& 6$ with those important variables and then evaluated according to Section 3.1.

$$
\begin{gathered}
R_{s}=a\left(1-\exp \left(-b \cdot \Delta T^{c}\right)\right) R_{a} \cdot A+p_{n+1} \\
A=1+\sum_{j=1}^{n} p_{j} \cdot v_{j}
\end{gathered}
$$

Where, $A$ is the adjustment of the $B C$ model according to the evaluation of variable importance, $p$ is the parameter related to the variable $v$ and $n$ is the number of variables of adjustment.

\section{Results and discussion}

\subsection{Model building}

The evaluation of variable importance for La Rioja is collated in Table 3. $\Delta T, H$, and $M$ show values of $R^{2}$ higher than 0.15 . Throughout the analysis of variable importance it might be proved that rainfall in this region should be explained with $M$ instead of $P$ ( 0.153 vs. 0.056$)$, which however, is implemented in models 6 and 7. As a result, $P$ is rejected as a variable 
to explain $R_{s}$. Equation 6 might be fitted with different combinations of variables $\left(p_{j}\right)$ and therefore, different models might be built and then evaluated as per Section 3.1. Two different sets of models are built regarding inputs used. The first set of models, constituted by 9 models, is built considering commonly registered meteorological variables $\left(T_{\max }, T_{\min }\right.$ and $\left.M\right)$. The second set of models also integrates $W$ and $H$ and is composed by 3 different models. Since $\Delta T$ is already considered within the $B C$ model, only $\Delta T_{j \neq 1}$ are considered in $A$. Eventually, only $p_{j}$ and $p_{j \pm 1}$ are relevant in $R_{s}$, showing lower errors in the evaluation. $M_{j}, M_{j \pm 1}, \Delta T_{j}$ and $\Delta T_{j \pm 1}$ provide information about the cloud coverage [23] and $W$ and $H$ refine the sky clearness. However, $H_{j \neq 1}$ and $W_{j \neq 1}$ reduce the robustness of models and increase errors. $M, M_{i-1}$ and $M_{i+1}$ were already implemented in the [29] models (models 18 and 19). Equations 6 and 7 show the final models proposed for both afore-mentioned sets.

$$
R_{s}=R_{a} \cdot a\left(1-\exp \left(-b \cdot \Delta T^{c}\right)\right) \cdot\left(1+d \cdot M_{j-1}+e \cdot M_{j}+f \cdot M_{j+1}+g \cdot \Delta T_{j+1}+h \cdot \Delta T_{j-1}\right)+l
$$

$R_{s}=R_{a} \cdot a\left(1-\exp \left(-b \cdot \Delta T^{c}\right)\right) \cdot\left(1+d \cdot M_{j-1}+e \cdot M_{j}+f \cdot M_{j+1}+g \cdot \Delta T_{j+1}+h \cdot \Delta T_{j-1}+l \cdot W_{j}+m \cdot H_{j}\right)+n$

\subsection{Evaluation of parametric models}

The results of the robustness assessment are collated in Figure 2, showing the 95\% confidence intervals $(95 \%$ C.I., $\mathrm{n}=100)$ of the $M A E_{\text {val }}$ obtained by bootstrapping and also the test errors $\left(M A E_{t e s}\right)$. Narrow confidence intervals and low values of $M A E_{\text {val }}$ imply both stability and accuracy in models, and low $M A E_{\text {tes }}$ means high capacity for generalization within the testing period. Several models, such as 12 and 13 at station 1, 12-14 at station 8, 10 and 12 at the station 12, and 1-5, 7-10, 12 and 20 at the station 17 among others, generate wide confidence intervals and high values of $M A E_{v a l}$ and at the same time low $M A E_{t e s}$. In spite of the high capacity for generalization of the afore-mentioned models within the testing period, the methodology proposed leads to their selection being avoided. For instance, stable and accurate models such as 24 should be selected at station 17 instead of model 20, although the latter generates lower $M A E_{t e s}$. The robustness assessment is found useful when only short and biased time series are available to evaluate models.

The stability of models is assessed through the $\overline{R_{M A E, v a l}}$ of the model for the whole set of stations (Table 4). The proposed models (models 23 and 24) improve the results of [29] (models 18 and 19) with $\overline{R_{M A E, v a l}}$ of 0.360 and $0.261 \mathrm{MJ} / \mathrm{m}^{2}$ day and 0.387 and $0.385 \mathrm{MJ} / \mathrm{m}^{2}$ day, respectively. Therefore, model 23 is considered the most stable for this region by means of rainfall and daily range of temperatures. However, a significant improvement in stability is achieved introducing $W$ and $H$ in addition to $\Delta T$ and $M$, as seen with model 24. Models 1-10, 15, 20 and 22 generate similar $\overline{R_{M A E, v a l}}$ between [0.42-0.45] MJ/m² day, and models 12-14, 17 and 21 between [0.48-0.53] MJ/m² day. The low stability of models 11 and 16 , with $\overline{R_{M A E, v a l}}$ of 0.761 and 0.764 $\mathrm{MJ} / \mathrm{m}^{2}$ day, might be explained by the inclusion of $R_{a, i-30}$ and the lack of $R_{a}$, respectively.

Model accuracy is assessed via the average of $M A E_{v a l}$ for the whole set of stations $\left(\overline{M A E_{v a l}}\right)$. The highest accuracy in predictions is also achieved with models 24,23 and 18 with $\overline{M A E_{v a l}}$ of 2.195, 2.247 and $2.317 \mathrm{MJ} / \mathrm{m}^{2}$ day (Table 4). In addition, model 23 and 24 obtain the lowest values of $M A E_{v a l}$ of $1.886 \pm 0.161$ and $1.887 \pm 0.090$ (95\% C.I., $\left.\mathrm{n}=100\right) \mathrm{MJ} / \mathrm{m}^{2}$ day (Figure 2) at station 11 (Calahorra). According to the $t$-test the $M A E_{v a l}$ mean is statistically lower in model 24 than any other model in all stations, except in station 9, in which models 18, 19 and 23 have lower $M A E_{\text {val }}$ mean (Table 5). From this test, it can also be deduced that model 23 has statistically lower $M A E_{\text {val }}$ than models 18 and 19 in all stations. 
The original $B C$ model (model 8) achieves lower $\overline{M A E_{v a l}}\left(2.617 \mathrm{MJ} / \mathrm{m}^{2}\right.$ day) than other $B C$ derived models such as 10-14 and 20-21. Models 3, 5 and 6, derived from [9] (model 1), obtain lower $\overline{M A E_{\text {val }}}$ than the initial model. [10] (model 7), derived from [22] (model 15) improves the $\overline{M A E_{\text {val }}}$ from $2.719 \mathrm{MJ} / \mathrm{m}^{2}$ day (model 15$)$ to $2.534 \mathrm{MJ} / \mathrm{m}^{2}$ day (model 7). [30] and [31] models (models 16 and 17), in which $\Delta T$ is not considered, achieve $\overline{M A E_{v a l}}$ of $6.315 \mathrm{MJ} / \mathrm{m}^{2}$ day and $3.405 \mathrm{MJ} / \mathrm{m}^{2}$ day. [38] (model 11) generates a $M A E_{\text {val }}$ of $4.426 \mathrm{MJ} / \mathrm{m}^{2}$ day, due to its high dependency on the $R_{a, i-30}$.

The capacity of generalization of models to non-common days is assessed through the $\overline{R M S E_{v a l}}$ and $\overline{R_{R M S E, v a l}}$ in Table 4. The model proposed (model 24) behaves with lower $\overline{R M S E_{\text {val }}}(2.879$ $\mathrm{MJ} / \mathrm{m}^{2}$ day) than the other models analyzed and also with a lower $\overline{R_{R M S E, v a l}}\left(0.361 \mathrm{MJ} / \mathrm{m}^{2}\right.$ day $)$. This model generates lower median of $R M S E_{v a l}$ in all stations, except in station 9 , in which is lower in models 18, 19 and 23.

Eventually, the models 24 (model proposed by means of $\Delta T, M, W$ and $H$ ) and model 23 (model proposed by means of $\Delta T$ and $M$ ) are considered the most suitable models for estimating $R_{s}$ in La Rioja. Notwithstanding, the model evaluation is focused on model 24 due to its superior stability and accuracy. $41.65 \%$ of the daily residuals in the case of SIAR and $20.12 \%$ in that of SOS Rioja fall within the uncertainty tolerance of the pyranometers of the two networks ( $10 \%$ and $5 \%$, respectively). However, smaller differences between $R_{s, \text { meas }}$ and $R_{s, e s t}$ are found in Figure 4 when considering yearly sums of $R_{s}$. Yearly sums of $R_{S}$ fall within the uncertainty tolerance of the pyranometers in all estations during the five years (2007-2011) with a higher divergence of $4.823 \%$ in 2011. Regarding the relative differences between measured and estimated monthly sums of $R_{S}$ in $2011,91.7 \%$ and $45.8 \%$ of the cases in SIAR and SOS Rioja stand within the tolerance of pyranometers.

The performance of the whole set of models is related to elevation, as shown in Figure 5, with higher $M A E_{\text {val }}$ being produced at higher altitudes, as evidenced at stations over 1000 $\mathrm{m}$. A suitable explanation of this behabiour might be because there is more meteorological variability in the mountainous areas of La Rioja, than in the lowlands [26]. A slight correlation with elevation is found in models 10, 14 18-20, 23 and 24, not as marked as with other models.

Figure 6 shows the parameters calibrated on model 24 to estimate $R_{s}$ in $W h / m^{2}$ day. High variability between stations is found within the non explanatory constant (parameter $n$ ). This variability was also reported by [29] and might be explained by the strong site dependency described by [26, 62]. [23] and [19] described correlations between the parameters and the distance between stations or latitude and longitude. Nevertheless, no correlation between the values of the parameters and latitude, longitude, elevation or distance between stations is found in model 24.

The effect of rain in model 24 is shown in Figure 7, in which the MAE of non-rainy days is on average $11.3 \%$ lower than that of rainy days for the whole set of stations. This is also widely found in the rest of the models, and is explained by the fact that solar irradiation is more complex on rainy and overcast days [10]. 2011 was an especially dry year in La Rioja, with $19.7 \%$ less rainfall than the average for the calibration period 2007-2010 (Table 2), so the $M A E_{\text {tes }}$ figures are significantly low in comparison with the confidence intervals of the $M A E_{\text {val }}$ in Figure 2. However, this tendency is broken with some models at station 14 (Moncalvillo), where the $M A E_{t e s}$ are higher than the $M A E_{\text {val }}$. More cloud cover in the testing period, evidenced by $\overline{\Delta T_{t}}$ being lower that the $\overline{\Delta T_{c}}$ seen in Table 2 at station 18, might explain this finding [23].

\subsection{Evaluation compared with CM SAF}

The mean MAE registered by CM SAF related to $R_{s, \text { meas }}$ is $1.983 \mathrm{MJ} / \mathrm{m}^{2}$ day with a standard deviation of $0.517 \mathrm{MJ} / \mathrm{m}^{2}$ day, in average $10.7 \%$ lower than $\overline{M A E_{v a l}}$ from model 24 , although in stations $9,11,14,16$ and $17 M A E_{C M S A F}$ is higher than the confidence interval (95\% C.I., 
$\mathrm{n}=100$ ). The $R M S E_{C M S A F}$ is $3.207 \mathrm{MJ} / \mathrm{m}^{2}$ day with a standard deviation of $0.449 \mathrm{MJ} / \mathrm{m}^{2}$ day, being higher than the confidence interval (95\% C.I., $\mathrm{n}=100)$ in stations $6,7,9,12,14,16$ and 17. Table 6 shows the errors of testing (testing dataset) for the model 24 and CM SAF. It might be deduced that CM SAF generally performs with lower errors than model 24 except in stations 9, 11, 14, 16 and 17 (same stations with lower $M A E_{v a l}$ and $R M S E_{v a l}$ than CM SAF), in which model 24 is superior.

Figure 3 shows the performance of model 24 with new data from the testing database. This model achieves coefficients of determination $\left(R^{2}\right)$ with linear regression of [0.87-0.91] and [0.790.87] for stations below and above $1000 \mathrm{~m}$ respectively. The coefficients of determination from CM SAF against $R_{s, \text { meas }}\left(R_{C M S A F}^{2}\right)$ are significantly higher than $R^{2}$, but also showing a relation with elevation, being lower at higher elevation.

The annual irradiation estimated by CM SAF is significantly higher than the $R_{s, \text { meas }}$, which was also found in Spain by [63]. Stations 11,14, 16 and 17 present relative differences substantially above the tolerance of pyranometers reaching $22.95 \%$ in station 14 in year 2011 . Thus, the model proposed (model 24) is able to estimate more accurately annual irradiation in this region than the CM SAF during years 2007-2011.

It could be argued that, because the CM SAF estimations show higher $R^{2}$ values, their worse results in the RMSE and MAE indicators may be improved with a local calibration. This approach was developed in [63] with a geostatistical interpolation (kriging with external drift) using data from a network of 301 ground stations and also CM SAF. A more simplified approach is to use a parametric model as Equation 9,

$$
R_{s}=R_{a} \cdot\left(a \cdot \frac{R_{s, c m s a f}}{R_{a}}+b\right)
$$

where the CMSAF estimations are normalized with the extraterrestial radiation and calibrated with the on-ground radiation measurements. This approach has been analyzed achieving $\overline{M A E_{\text {val }}}$ and $\overline{R M S E_{\text {val }}}$ of 1.913 and $2.987 \mathrm{MJ} / \mathrm{m}^{2}$ day with $\overline{R_{M A E, v a l}}$ and $\overline{R_{R M S E, v a l}}$ of 0.422 and $0.886 \mathrm{MJ} / \mathrm{m}^{2}$ day, respectively. The $R^{2}$ in this parametrization is also lowered respect the actual $R^{2}$ of CM SAF. This means that it is only improved the $\overline{M A E_{\text {val }}}$ respect to the model 24 while getting the other indicators worse. However, this re-calibration of CM SAF leads to lower errors in annual sums of global irradiation with CM SAF (in 15 stations the error is within the $5 \%$ and a $5.7 \%$ maximum error). The Table 7 shows parameters of Equation 9, where $a_{\text {mean }}$, $b_{\text {mean }}, a_{s d}, b_{s d}$ are the average and standard deviations of $a$ and $b$.

\section{Conclusions}

The methodology proposed of model development of adjusting a general model with the onsite peculiarities based on the evaluation of variable importance is proved appropiated within the case study of La Rioja region (northern Spain). The high site dependency of $R_{S}$ related to the meteorological trends suggests the adjustment of general parametric models (such as the $B C$ and [9] models) with those variables that show higher correlation with $R_{s}$. By means of this methodology, different models might be proposed in locations with different climates. The new model includes $M, M_{i-1}, M_{i+1}, \Delta T_{i-1}, \Delta T_{i+1}, W, H$ as explanatory variables (derived from the evaluation of variable importance) that adjust the $B C$ model in La Rioja.

The methodology proposed of model evaluation is based on bootstrapping and proves useful in selecting models according to stability and accuracy and not only based on test errors. The proposed model is evaluated with this methodology against a review of twenty-two already existing parametric models at seventeen meteorological stations within La Rioja. The new model improves the estimates of the other twenty-two models with $\overline{M A E_{v a l}}$ of $2.195 \mathrm{MJ} / \mathrm{m}^{2}$ day and 
$\overline{R_{M A E, v a l}}$ of $0.261 \mathrm{MJ} / \mathrm{m}^{2}$ day. However, several BC derived models $(10-14,20-21)$ fail to improve the estimates of the original model. This might be explained because these models include variables that do not show high correlation with $R_{s}$ (such as $P$ ) within La Rioja. In addition, significant differences in stability between models and meteorological stations are recorded with these models. The performance of the model proposed is compared with $R_{S, C M S A F}$, obtaining lower confidence interval ( $95 \%$ C.I., $\mathrm{n}=100)$ of $M A E_{\text {val }}$ than $M A E_{C M S A F}$ in 5 stations and for $R M S E_{\text {val }}$ in 7 stations.

Rainfall and elevation are shown to influence the accuracy of model performance (generating higher errors in rainy days and also at higher stations). The fact that the testing dataset (year 2011) was significantly drier than the calibration dataset (years 2007-2010) explains the low $M A E_{\text {tes }}$ recorded.

The residuals of estimates are found to have yearly periodicity, with higher relative residuals when meteorological variability is greater. $41.65 \%$ of the daily residuals in the case of SIAR and $20.12 \%$ in that of SOS Rioja fall within the uncertainty tolerance of the pyranometers of the two networks (10\% and $5 \%$, respectively). However, the annual relative differences between $R_{s, \text { meas }}$ and $R_{s, e s t}$ are lower than $4.82 \%$, which means that estimates are within the confidence interval of pyranometers.

The analysis of parametric models against the CM SAF satellite-derived irradiation data shows that the mean $M A E_{C M S A F}$ is in average $10.7 \%$ lower than $\overline{M A E_{v a l}}$, but also that in 5 stations the $\overline{M A E_{v a l}}$ is significantly lower than the one of CM SAF. This tendence is also common with the RMSE, which is generally lower with CM SAF, but not always (7 stations). Nevertheless, attending to the annual irradiation it has been proved that the model proposed (model 24) achieves significantly better estimates that the CM SAF, which over-estimates solar irradiation within the region studied. The possibility of shades on the positions of stations over the CM SAF estimates has been previously analyzed and rejected. As a result, the proposed model might be useful to estimate annual sums of $R_{s}$, reaching insignificant differences with $R_{s}$ from pyranometers and also to be used on a daily basis when correctly calibrated with on-ground data.

\section{Acknowledgements}

We are indebted to the University of La Rioja (fellowship FPI 2012) and the Research Institute of La Rioja (IER) for funding parts of this research.

\section{References}

[1] Running, S. W., Nemani, R. R., Hungerford, R. D., 1987. Extrapolation of synoptic meteorological data in mountainous terrain and its use for simulating forest evapotranspiration and photosynthesis. Can. J. For. Res. 17, 472-483.

[2] Crop Growth Monitoring System URL http://www. marsop.info/marsopdoc/cgms92/2_2_2_en.htm

[3] Beyer, H. G., Polo-Martinez, J., Suri, M., Torres, J. L., Lorenz, E., Muller, S. C., Hoyer-Klick, C., Ineichen, P., 2009. Mesor: Management and exploitation of solar resource knowledge. D 1.1.3 Report on Benchmarking of Radiation Products., 1-160.

[4] Schulz, J., Albert, P., Behr, H.-D., Caprion, D., Deneke, H., Dewitte, S., Dürr, B., Fuchs, P., Gratzki, A., Hechler, P., Hollmann, R., Johnston, S., Karlsson, K.-G., Manninen, T., Müller, R., Reuter, M., Riihelä, A., Roebeling, R., Selbach, N., Tetzlaff, A., Thomas, W., Werscheck, 
M., Wolters, E., Zelenka, A., 2009. Operational climate monitoring from space: the EUMETSAT satellite application facility on climate monitoring (CM-SAF). Atmos. Chem. Phys. 9 (5), 1687-1709.

[5] Posselt, R., Mueller, R., Stockli, R., Trentmann, J., 2012. Remote sensing of solar surface radiation for climate monitoring - the CM-SAF retrieval in international comparison. Remote Sens. Environ. 118 (0), 186 - 198.

[6] Rahimikhoob, A., 2010. Estimating global solar radiation using artificial neural network and air temperature data in a semi-arid environment. Renew. Energ. 35 (9), 2131 - 2135.

[7] Senkal, O., 2010. Modeling of solar radiation using remote sensing and artificial neural network in Turkey. Energy 35 (12), 4795 - 4801.

[8] Bristow, K. L., Campbell, G. S., 1984. On the relationship between incoming solar radiation and daily maximum and minimum temperature. Agric. For. Meteorol. 31 (2), 159 - 166.

[9] Hargreaves, G. H., 1981. Responding to tropical climates. In: 1980-81 Food and Climate Review. The Food and Climate Forum. Aspen Institue for Humanistic Studies, Boulder, Colorado, pp. 29-32.

[10] Jong, R. D., Stewart, D. W., 1993. Estimating global solar radiation from common meteorological observations in western Canada. Can. J. Plant Sci. 73 (2), 509-518.

[11] The Satellite Application Facility on Climate Monitoring (CM SAF)

URL http: //www. cmsaf .eu

[12] SODA

URL http://www. soda-is.com/eng/index.html

[13] INPE

URL http://www.inpe.br

[14] National and Renewable Energy Laboratory (NREL)

URL http://www.nrel.gov/gis/solar.html

[15] NASA Surface meteorology and Solar Energy (SSE)

URL http://maps.nrel.gov/SWERA

[16] Perez, R., Seals, R., Stewart, R., Zelenka, A., Estrada-Cajigal, V., 1994. Using satellitederived insolation data for the site/time specific simulation of solar energy systems. Solar Energy 53 (6), 491-495.

[17] Angstrom, A., 1924. Solar and terrestrial radiation. Report to the international commission for solar research on actinometric investigations of solar and atmospheric radiation. Q. J. Roy. Meteor. Soc. 50 (210), 121-126.

[18] Prescott, J., 1940. Evaporation from a water surface in relation to solar radiation. Trans. R. Soc. So. Augst. 64, 114-125.

[19] Liu, X., Mei, X., Li, Y., Wang, Q., Jensen, J. R., Zhang, Y., Porter, J. R., 2009. Evaluation of temperature-based global solar radiation models in China. Agric. For. Meteorol. 149 (9), $1433-1446$. 
[20] Supit, I., van Kappel, R., 1998. A simple method to estimate global radiation. Sol. Energy $63(3), 147-160$.

[21] Ododo, J., 1997. Prediction of solar radiation using only maximum temperature and relative humidity: south-east and north-east Nigeria. Energy Convers. Manage. 38 (18), 1807 1814.

[22] Richardson, C. W., 1981. Stochastic simulation of daily precipitation, temperature, and solar radiation. Water Resour. Res. 17 (1), 182-190.

[23] Trnka, M., Zalud, Z., Eitzinger, J., Dubrovsky, M., 2005. Global solar radiation in Central European lowlands estimated by various empirical formulae. Agric. For. Meteorol. 131 (12), $54-76$.

[24] Allen, R. G., 1995. Evaluation of procedures for estimating mean monthly solar radiation from air temperature. Report. Food and Agricultural Organization of the United Nations (FAO), Rome., Rome.

[25] Allen, R. G., 1997. Self-calibrating method for estimating solar radiation from air temperature. J. Hydrol. Eng. 2 (2), 56-67.

[26] Annandale, J. G., Jovanovic, N. Z., Benade, N., Allen, R. G., Mar. 2002. Software for missing data error analysis of Penman-Monteith reference evapotranspiration. Irrig. Sci. 21 (2), 57 67.

[27] Chen, R., Ersi, K., Yang, J., Lu, S., Zhao, W., 2004. Validation of five global radiation models with measured daily data in China. Energy Convers. Manage. 45, 1759 - 1769.

[28] Hunt, L., Kuchar, L., Swanton, C., 1998. Estimation of solar radiation for use in crop modelling. Agric. For. Meteorol. 91, 293 - 300.

[29] Liu, D., Scott, B., 2001. Estimation of solar radiation in Australia from rainfall and temperature observations. Agric. For. Meteorol. 106 (1), 41 - 59.

[30] McCaskill, M., 1990. An efficient method for generation of full climatological records from daily rainfall. Aust. J. Agric. Res. Aust. J. Agric. Res., 595-602.

[31] McCaskill, M., 1990. Prediction of solar radiation from rainday information using regionally stable coefficients. Agric. For. Meteorol. 51, 247-255.

[32] Weiss, A., Hays, C. J., 2004. Simulation of daily solar irradiance. Agric. For. Meteorol. 123, $187-199$.

[33] Meza, F., Varas, E., 2000. Estimation of mean monthly solar global radiation as a function of temperature. Agric. For. Meteorol. 100, 231 - 241.

[34] Prieto, J., Martínez-García, J., García, D., 2009. Correlation between global solar irradiation and air temperature in Asturias, Spain. Sol. Energy 83 (7), 1076 - 1085.

[35] Abraha, M., Savage, M., 2008. Comparison of estimates of daily solar radiation from air temperature range for application in crop simulations. Agric. For. Meteorol. 148 (3), $401-$ 416.

[36] Donatelli, M., Campbell, G., 1998. A simple model to estimate global solar radiation. In: Proc. ESA Cong., 5th, Nitra, Slovak Republic, 28 June- 2 July, 1998. The Slovak Agriculture University, 133-134. 
[37] Goodin, D. G., Hutchinson, J. M. S., Vanderlip, R. L., Knapp, M. C., 1999. Estimating solar irradiance for crop modeling using daily air temperature data. Agron. J. 91 (5), 845-851.

[38] Weiss, A., Hays, C. J., Hu, Q., Easterling, W. E., 2001. Incorporating bias error in calculating solar irradiance: Implications for crop yield simulations. Agron. J. 93 (6), 1321-1326.

[39] Almorox, J., Hontoria, C., Benito, M., 2011. Models for obtaining daily global solar radiation with measured air temperature data in Madrid (Spain). Appl. Energ. 88 (5), 1703 1709.

[40] Mavromatis, T., Jagtap, S. S., 2005. Estimating solar radiation for crop modeling using temperature data from urban and rural stations. Climate Res. 29 (3), 233-243.

[41] Thornton, P. E., Running, S. W., 1999. An improved algorithm for estimating incident daily solar radiation from measurements of temperature, humidity, and precipitation. Agric. For. Meteorol. 93 (4), $211-228$.

[42] Winslow, J. C., Hunt, E. R., Piper, S. C., 2001. A globally applicable model of daily solar irradiance estimated from air temperature and precipitation data. Ecol. Model. 143 (3), 227 $-243$.

[43] Korpela, M., Mäkinen, H., Nöjd, P., Hollmén, J., Sulkava, M., Jun. 2010. Automatic detection of onset and cessation of tree stem radius increase using dendrometer data. Neurocomputing 73, 2039-2046.

[44] Sos Rioja URL http://www. larioja.org/npRioja/default/defaultpage.jsp?idtab=441001

[45] Siar URL http://ias1.larioja.org/estaciones/estaciones/siar/portada/index.jsp

[46] Lawrence, S., Giles, C. L., Tsoi, A. C., 1996. What size neural network gives optimal generalization? Convergence properties of backpropagation. Technical Report UMIACS-TR96-22 and CS-TR-3617. Institute for Advanced Computer Studies. University of Maryland College Park, MD 20742, 1-35.

[47] Crawley, M. J., 2005. Statistics: an introduction using R. John Wiley.

[48] Mora, J., Mora-López, L., 2010. Comparing distributions with bootstrap techniques: An application to global solar radiation. Math. Comput. Simulat. 81 (4), $811-819$.

[49] Varadhan, R., 2012. BB: Solving and optimizing large-scale nonlinear systems, $r$ package version 2012.3-1 (2012).

URL URLhttp://cran.r-project.org/web/packages/BB/BB.pdf

[50] Broyden, C. G., 1970. The convergence of a class of double-rank minimization algorithms. General considerations. IMA J. Appl. Math. 6 (1), 76-90.

[51] Nielsen, H., Mortensen, S., 2007. ucminf: General-purpose unconstrained non-linear optimization.

URL http://CRAN . R-project. org/package=ucminf

[52] Willmott, C. J., Matsuura, K., 2005. Advantages of the mean absolute error (MAE) over the root mean square error (RMSE) in assessing average model performance. Climate Res. 30 (1), 79-82. 
[53] Moreno, A., Gilabert, M., Martínez, B., 2011. Mapping daily global solar irradiation over Spain: A comparative study of selected approaches. Sol. Energy 85 (9), $2072-2084$.

[54] R Development Core Team, 2012. R: A language and environment for statistical computing. R Foundation for Statistical Computing, Vienna, Austria, ISBN 3-900051-07-0. URL http://www.R-project.org

[55] Pebesma, E. J., 2004. Multivariable geostatistics in s: the gstat package. Comput. Geosci. $30,683-691$.

[56] Pebesma, E. J., Bivand, R. S., November 2005. Classes and methods for spatial data in R. R News 5 (2), 9-13.

URL http://CRAN.R-project.org/doc/Rnews/

[57] Nash, J. C., Varadhan, R., 2012. optimx: A replacement and extension of the optim() function.

URL http://cran.r-project.org/web/packages/optimx/index.html

[58] Perpiñán, O., 2012. solaR: Solar radiation and photovoltaic systems with R. J. Stat. Softw. $50(9), 1-32$.

URL http://www. jstatsoft.org/v50/i09/

[59] Hijmans, R. J., van Etten, J., 2012. raster: Geographic analysis and modeling with raster data.

URL http://cran.r-project.org/web/packages/raster/

[60] Perpiñán, O., Hijmans, R., 2012. rasterVis: Visualization methods for the raster package. R package version $0.10-9$.

URL http: //CRAN.R-project.org/package=rasterVis

[61] Cleveland, W., 1979. Robust locally weighted regression and smoothing scatterplots. Journal of the American Statistical Association 74 (368): 829-836.

[62] Gueymard, C., Jindra, P., Estrada-Cajigal, V., 1995. A critical look at recent interpretations of the Angstrom approach and its future in global solar radiation prediction. Sol. Energy $54(5), 357-363$.

[63] Antonanzas-Torres, F., Cañizares, F., Perpiñán, O., 2013. Comparative assessment of global irradiation from a satellite estimate model (CMSAF) and on-ground measurements (SIAR): a Spanish case study. Renew. Sust. Energ. Rev. 21 248-261.

\begin{tabular}{lcll}
\hline $\begin{array}{l}\text { Model } \\
\text { no. }\end{array}$ & Equation & Parameters & Authors \\
\hline 1 & $R_{s}=a \sqrt{\Delta T} R_{a}$ & a & [9] \\
& $R_{s}=a\left(1+2.7 \cdot 10^{-5} \cdot h\right) \sqrt{\Delta T} R_{a}$ & a & [26] \\
\hline 2 & & \\
\hline
\end{tabular}




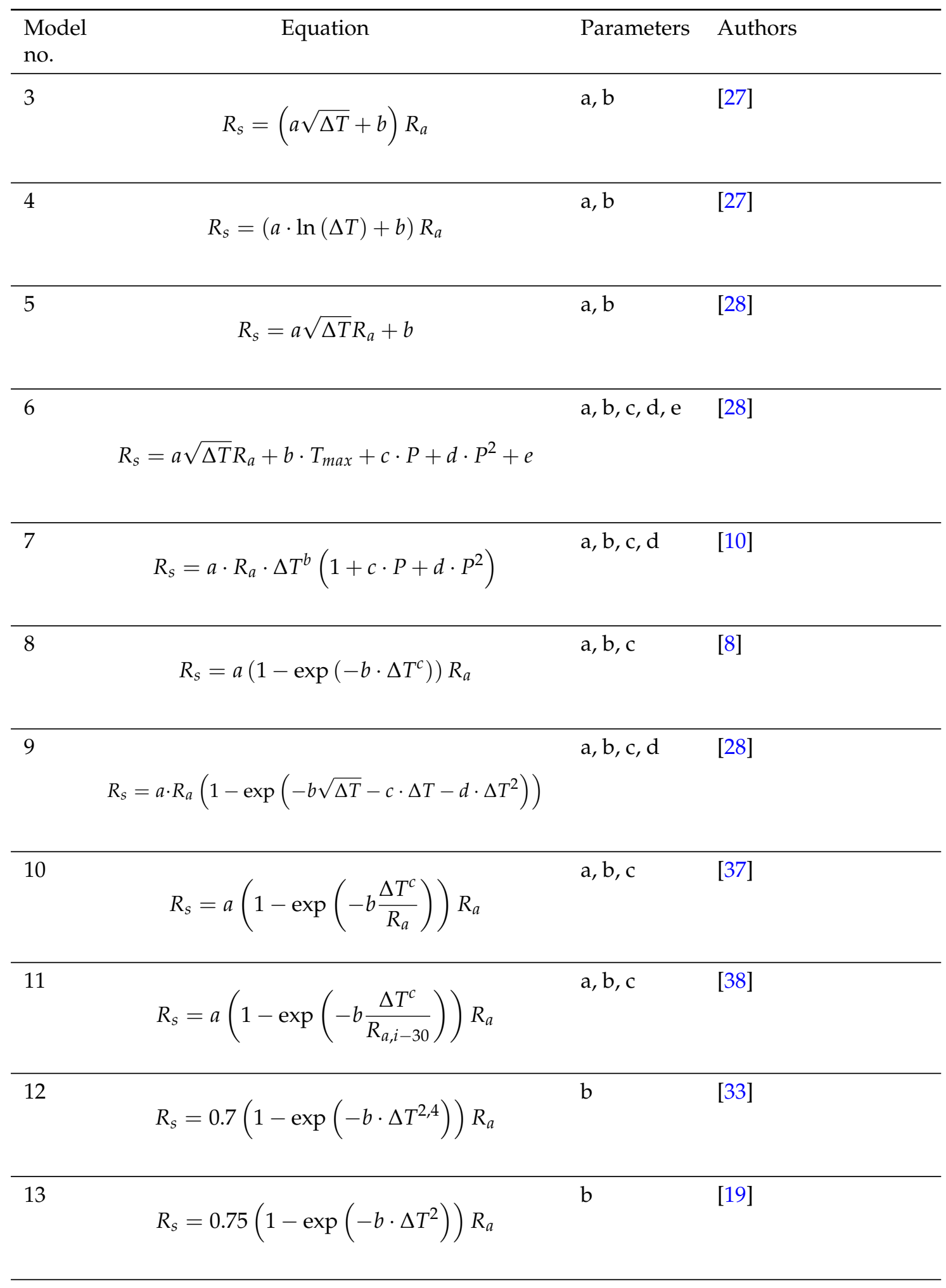




\begin{tabular}{|c|c|c|c|}
\hline $\begin{array}{l}\text { Model } \\
\text { no. }\end{array}$ & Equation & Parameters & Authors \\
\hline 14 & $R_{S}=0.75\left(1-\exp \left(-b \cdot \frac{\Delta T^{2}}{\Delta T_{m}}\right)\right) R_{a}$ & $\mathrm{~b}$ & [19] \\
\hline 15 & $R_{s}=\left(a \cdot \Delta T^{b}\right) R_{a}$ & $a, b$ & [22] \\
\hline 16 & $\begin{aligned} R_{s}=a+b & \cdot \cos (\theta)+c \cdot \sin (\theta) \\
+d \cdot & \cos (2 \theta)+e \cdot \sin (2 \theta) \\
& +f \cdot M_{j-1}+g \cdot M_{j}+h \cdot M_{j+1}\end{aligned}$ & $\begin{array}{l}a, b, c, d, e, \\
f, g, h\end{array}$ & [30] \\
\hline 17 & $R_{s}=a \cdot R_{a}+b \cdot M_{j-1}+c \cdot M_{j}+d \cdot M_{j+1}$ & $a, b, c, d$ & [31] \\
\hline 18 & $\begin{aligned} R_{s}= & R_{a} \cdot a\left(1-\exp \left(-b \cdot \Delta T^{c}\right)\right) \\
& \cdot\left(1+d \cdot M_{j-1}+e \cdot M_{j}+f \cdot M_{j+1}\right)+g\end{aligned}$ & $\begin{array}{l}a, b, c, d, e, \\
f, g\end{array}$ & [29] \\
\hline 19 & $\begin{aligned} R_{s}=R_{a} & \cdot a\left(1-\exp \left(-b \cdot \Delta T^{c}\right)\right) \\
& +d \cdot M_{j-1}+e \cdot M_{j}+f \cdot M_{j+1}+g\end{aligned}$ & $\begin{array}{l}a, b, c, d, e, \\
f, g\end{array}$ & [29] \\
\hline 20 & $R_{s}=a\left(1-\exp \left(-b \frac{\Delta T^{c}}{\Delta T_{m}}\right)\right) R_{a}$ & $a, b, c$ & [36] \\
\hline 21 & $\begin{array}{c}R_{s}=0.75\left(1-\exp \left(-b \cdot \Delta T^{2} \cdot f\left(T_{\text {avg }}\right)\right)\right) \\
f\left(T_{\text {avg }}\right)=0.017 \exp \left(\exp \left(-0.053 \cdot T_{\text {avg }} \cdot \Delta T\right)\right)\end{array}$ & $\mathrm{b}$ & [36] \\
\hline
\end{tabular}




\begin{tabular}{lll}
\hline $\begin{array}{l}\text { Model } \\
\text { no. }\end{array}$ & Equation & Parameters Authors \\
\hline
\end{tabular}

22
$a, b, c, d$
[39]

$R_{s}=a \cdot R_{a} \cdot \Delta T^{b}\left(1-\exp \left(-c \cdot p_{\text {sat }}\left[T_{\text {max }}\right]\right)\right)^{d}$

23

$a, b, c, d, e, \quad$ Proposed model

f, $g, h, 1$

$$
\begin{aligned}
& R_{s}=R_{a} \cdot a\left(1-\exp \left(-b \cdot \Delta T^{c}\right)\right) \\
& \cdot\left(1+d \cdot M_{j-1}+e \cdot M_{j}+f \cdot M_{j+1}+g \cdot \Delta T_{j+1}+h \cdot \Delta T_{j-1}\right)+l
\end{aligned}
$$

24

$$
\begin{array}{cc}
R_{s}=R_{a} \cdot a\left(1-\exp \left(-b \cdot \Delta T^{c}\right)\right) & \mathrm{e}, \mathrm{f}, \mathrm{g}, \mathrm{h}, \mathrm{l}, \\
\cdot\left(1+d \cdot M_{j-1}+e \cdot M_{j}+f \cdot M_{j+1}+g \cdot \Delta T_{j+1}+h \cdot \Delta T_{j-1}+l \cdot W_{j}+m \cdot H_{j}\right)+n
\end{array}
$$$$
\text { a, b, c, d, Proposed model }
$$

Table 1: Summary of the twenty-three parametric models studied. $\Delta T$ is the difference between $T_{\max }$ and $T_{\min } . R_{a, i-30}$ is the extraterrestrial irradiation on day $i-30, h$ is the elevation above sea level, $T_{a v g}$ is the daily average air temperature, $\Delta T_{m}$ is the monthly average of $\Delta T$ and $p_{\text {sat }}\left[T_{\text {max }}\right]$ is the vapor saturation pressure at $T_{\max }$

\begin{tabular}{llllllllllll}
\hline$\#$ & Name & Net. & Lat. $\left(^{\circ}\right)$ & Long. $\left(^{\circ}\right)$ & Alt. & $\overline{\Delta T_{c}}$ & $\overline{\Delta T_{t}}$ & $P_{c}$ & $P_{t}$ & $\overline{R_{s, c}}$ & $\overline{R_{s, t}}$ \\
\hline 1 & Agoncillo & SIAR & 42.46 & -2.29 & 342 & 12.3 & 12.6 & 484 & 318 & 14.7 & 15.3 \\
\hline 2 & Aldeanueva & SIAR & 42.22 & -1.90 & 390 & 11.1 & 11.4 & 405 & 327 & 15.4 & 15.4 \\
\hline 3 & Alfaro & SIAR & 42.15 & -1.77 & 315 & 12.5 & 12.9 & 335 & 364 & 15.3 & 15.2 \\
\hline 4 & Casalarreina & SIAR & 42.53 & -2.89 & 510 & 11.8 & 12.4 & 486 & 341 & 14.2 & 14.2 \\
\hline 5 & Cervera & SIAR & 42.00 & -1.89 & 495 & 13.9 & 14.3 & 356 & 331 & 15.2 & 15.0 \\
\hline 6 & Foncea & SIAR & 42.60 & -3.03 & 669 & 10.1 & 10.5 & 647 & 422 & 14.8 & 14.7 \\
\hline 7 & Leiva & SIAR & 42.49 & -3.04 & 595 & 11.4 & 11.5 & 499 & 379 & 14.5 & 14.4 \\
\hline 8 & Rincon & SIAR & 42.25 & -1.85 & 277 & 12.3 & 12.7 & 393 & 348 & 15.3 & 15.5 \\
\hline 9 & Urunuela & SIAR & 42.46 & -2.71 & 465 & 11.4 & 12.4 & 476 & 345 & 14.1 & 14.2 \\
\hline 10 & Aguilar & SOS & 41.96 & -1.96 & 752 & 9.3 & 9.7 & 463 & 236 & 14.5 & 14.7 \\
\hline 11 & Calahorra & SOS & 42.29 & -1.99 & 350 & 11.1 & 11.3 & 305 & 250 & 13.3 & 13.4 \\
\hline 12 & Ezcaray & SOS & 42.33 & -3.00 & 1000 & 10.3 & 10.7 & 538 & 381 & 13.6 & 13.6 \\
\hline 13 & Logroño & SOS & 42.45 & -2.74 & 408 & 10.1 & 10.3 & 423 & 212 & 14.3 & 14.3 \\
\hline 14 & Moncalvillo & SOS & 42.32 & -2.61 & 1495 & 7.8 & 7.7 & 567 & 429 & 12.0 & 11.9 \\
\hline 15 & San Roman & SOS & 42.23 & -2.45 & 1094 & 8.2 & 8.2 & 323 & 332 & 13.9 & 14.2 \\
\hline
\end{tabular}




\begin{tabular}{llllllllllll}
\hline$\#$ & Name & Net. & Lat. $\left(^{\circ}\right)$ & Long. $\left({ }^{\circ}\right)$ & Alt. & $\overline{\Delta T_{c}}$ & $\overline{\Delta T_{t}}$ & $P_{c}$ & $P_{t}$ & $\overline{R_{s, c}}$ & $\overline{R_{s, t}}$ \\
\hline 16 & Ventrosa & SOS & 42.17 & -2.84 & 1565 & 7.4 & 7.7 & 447 & 412 & 12.2 & 12.1 \\
\hline 17 & Villoslada & SOS & 42.12 & -2.66 & 1235 & 9.7 & 9.9 & 499 & 325 & 12.6 & 12.4 \\
\hline
\end{tabular}

Table 2: Summary of the seventeen meteorological stations. $\overline{\Delta T_{\mathcal{C}}}$ and $\overline{\Delta T_{t}}$ are the average $\Delta T$ of the calibration and testing datasets, respectively. $P_{c}$ is the yearly average rainfall in $\mathrm{mm}$ for the calibration dataset and $P_{t}$ is the yearly rainfall for the testing dataset. $\overline{R_{s, c}}$ and $\overline{R_{s, t}}$ are the daily average $R_{S}$ for the calibration and testing datasets, respectively

\begin{tabular}{clllllllllll}
\hline$v$ & $P_{i}$ & $P_{i+1}$ & $P_{i-1}$ & $M_{i}$ & $M_{i+1}$ & $M_{i-1}$ & $\Delta T_{i}$ & $\Delta T_{i+1}$ & $\Delta T_{i-1}$ & $\Delta T_{i+2}$ & $\Delta T_{i-2}$ \\
\hline$R^{2}$ & 0.056 & 0.012 & 0.016 & 0.153 & 0.068 & 0.059 & 0.533 & 0.359 & 0.340 & 0.301 & 0.172 \\
\hline$v$ & $\Delta T_{i+3}$ & $\Delta T_{i-3}$ & $W_{i}$ & $W_{i+1}$ & $W_{i-1}$ & $H_{i}$ & $H_{i+1}$ & $H_{i-1}$ & $H_{i+2}$ & $H_{i-2}$ & \\
\hline$R^{2}$ & 0.206 & 0.167 & 0.089 & 0.076 & 0.071 & 0.465 & 0.344 & 0.251 & 0.251 & 0.199 & \\
\hline
\end{tabular}

Table 3: Summary of variable importance results related to each variable $v$ 


\begin{tabular}{lllllllllllll}
\hline Model & 1 & 2 & 3 & 4 & 5 & 6 & 7 & 8 & 9 & 10 & 11 & 12 \\
\hline$\overline{M A E_{\text {val }}}$ & 2.814 & 2.809 & 2.699 & 2.679 & 2.797 & 2.768 & 2.534 & 2.617 & 2.613 & 2.791 & 4.426 & 2.791 \\
\hline$\overline{R_{M A E, \text { val }}}$ & 0.436 & 0.415 & 0.426 & 0.425 & 0.411 & 0.430 & 0.420 & 0.420 & 0.422 & 0.423 & 0.761 & 0.527 \\
\hline$\overline{R M S E_{\text {val }}}$ & 3.572 & 3.560 & 3.475 & 3.448 & 3.541 & 3.488 & 3.409 & 3.294 & 3.398 & 3.584 & 5.873 & 3.825 \\
\hline$\overline{R_{R M S E, \text { val }}}$ & 0.559 & 0.545 & 0.601 & 0.569 & 0.549 & 0.539 & 0.577 & 0.605 & 0.593 & 0.579 & 0.996 & 0.745 \\
\hline$\overline{\text { Model }}$ & 13 & 14 & 15 & 16 & 17 & 18 & 19 & 20 & 21 & 22 & 23 & 24 \\
\hline$\overline{M A E_{\text {val }}}$ & 2.804 & 2.751 & 2.719 & 6.273 & 3.366 & 2.317 & 2.336 & 2.678 & 2.728 & 2.723 & 2.247 & 2.195 \\
\hline$\overline{R_{M A E, \text { val }}}$ & 0.491 & 0.488 & 0.444 & 0.764 & 0.498 & 0.387 & 0.385 & 0.445 & 0.498 & 0.432 & 0.360 & 0.261 \\
\hline$\overline{\overline{R M S E}_{\text {val }}}$ & 3.798 & 3.708 & 3.485 & 7.377 & 4.256 & 3.023 & 3.081 & 3.457 & 3.693 & 3.504 & 2.995 & 2.879 \\
\hline$\overline{R_{R M S E, \text { val }}}$ & 0.715 & 0.691 & 0.583 & 0.802 & 0.649 & 0.548 & 0.538 & 0.606 & 0.694 & 0.576 & 0.543 & 0.361 \\
\hline
\end{tabular}

Table 4: Summary of statistics in MJ/m² day

\begin{tabular}{cccccccccccccccccc}
\hline Mod. 18 & 1 & 2 & 3 & 4 & 5 & 6 & 7 & 8 & 9 & 10 & 11 & 12 & 13 & 14 & 15 & 16 & 17 \\
\hline$p-$ value & 0.9 & 0.9 & 0.9 & 0.6 & 0.9 & 0.8 & 0.8 & 0.9 & 0.0 & 0.9 & 0.6 & 0.9 & 0.9 & 0.7 & 0.9 & 0.6 & 0.9 \\
\hline Mod. 23 & 1 & 2 & 3 & 4 & 5 & 6 & 7 & 8 & 9 & 10 & 11 & 12 & 13 & 14 & 15 & 16 & 17 \\
\hline$p-$ value & 0.9 & 0.9 & 0.9 & 0.9 & 0.9 & 0.7 & 0.4 & 0.9 & 0.0 & 0.9 & 0.7 & 0.6 & 0.9 & 0.7 & 0.3 & 0.6 & 0.9
\end{tabular}

Table 5: Summary of $p$-values of $t$ - test in the $M A E_{\text {val }}$ of model 24 against model 18 and model 23 ( $p$-values greater than 0.05 imply statistically significant lower $M A E_{\text {val }}$ in model 24) 


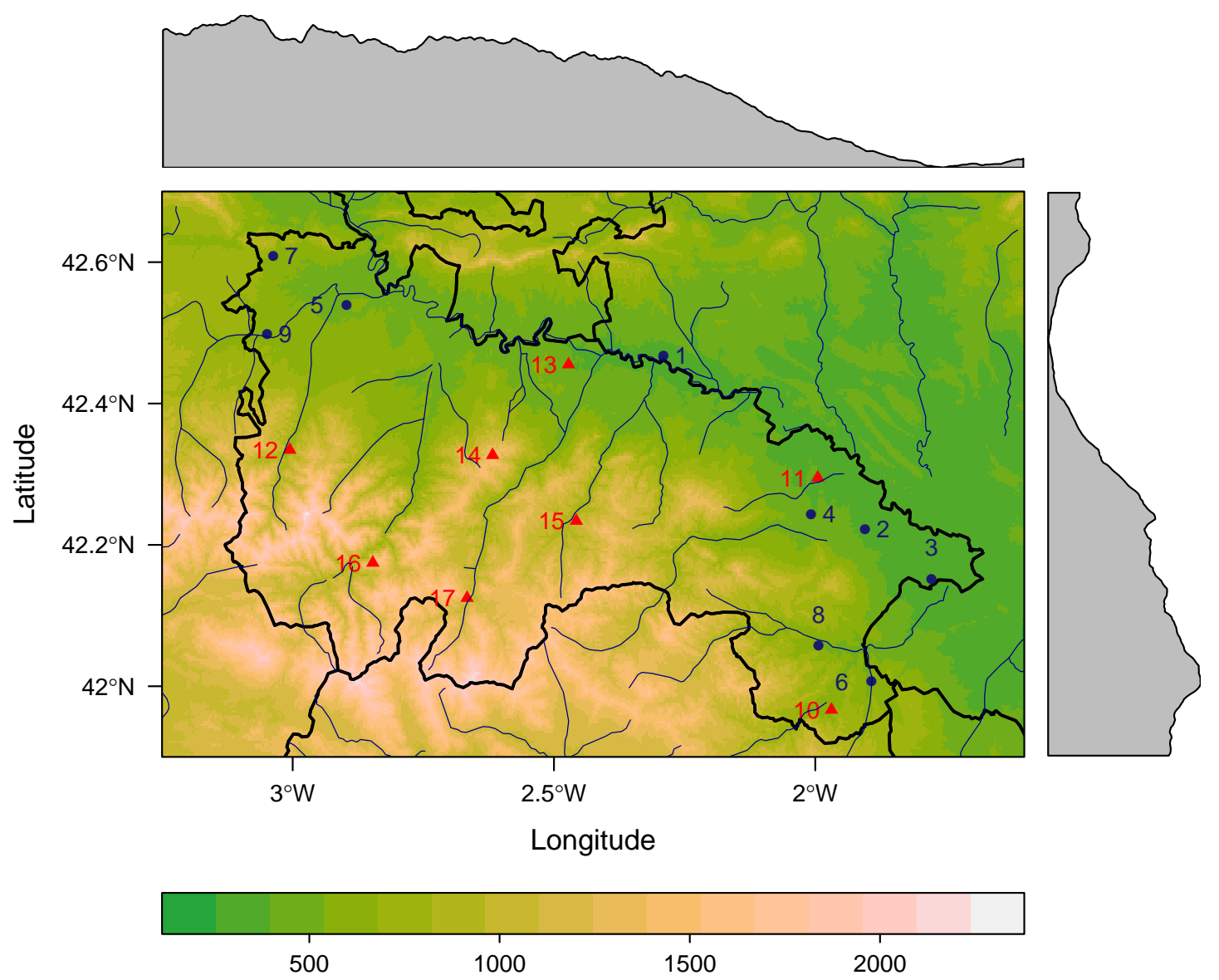

Figure 1: Location of the meteorological stations selected in the region of La Rioja. The color band represents elevation (m). SIAR stations are shown by blue circles and SOS Rioja stations by red triangles 


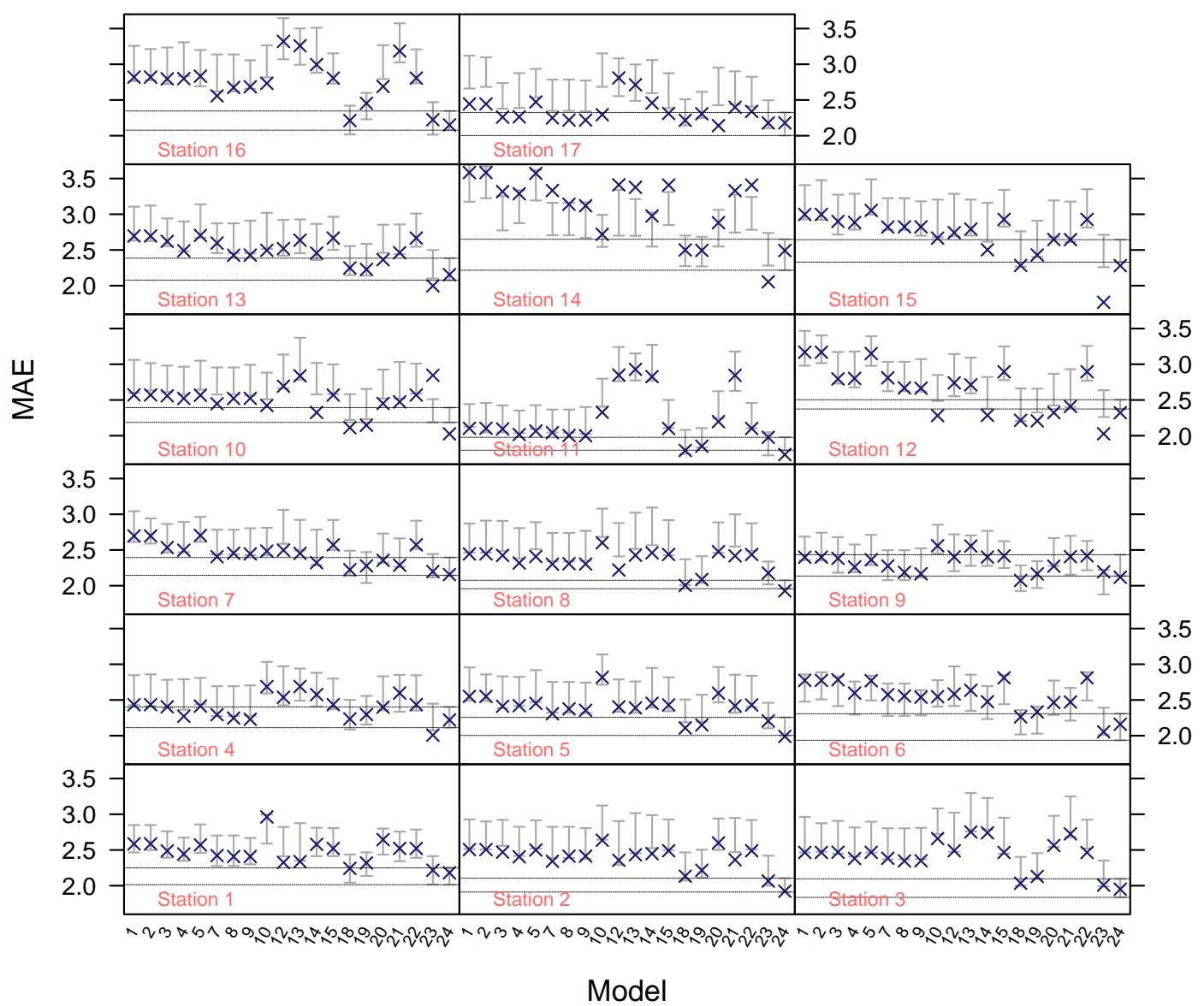

Figure 2: Confidence intervals (95\% C.I., $\mathrm{n}=100)$ of $M A E_{\text {val }}$ (grey vertical lines) and $M A E_{\text {tes }}$ (blue crosses) (MJ $/ \mathrm{m}^{2}$ day). Note that some of the values of models 11, 16 and 17 lie outside the range of the figure 


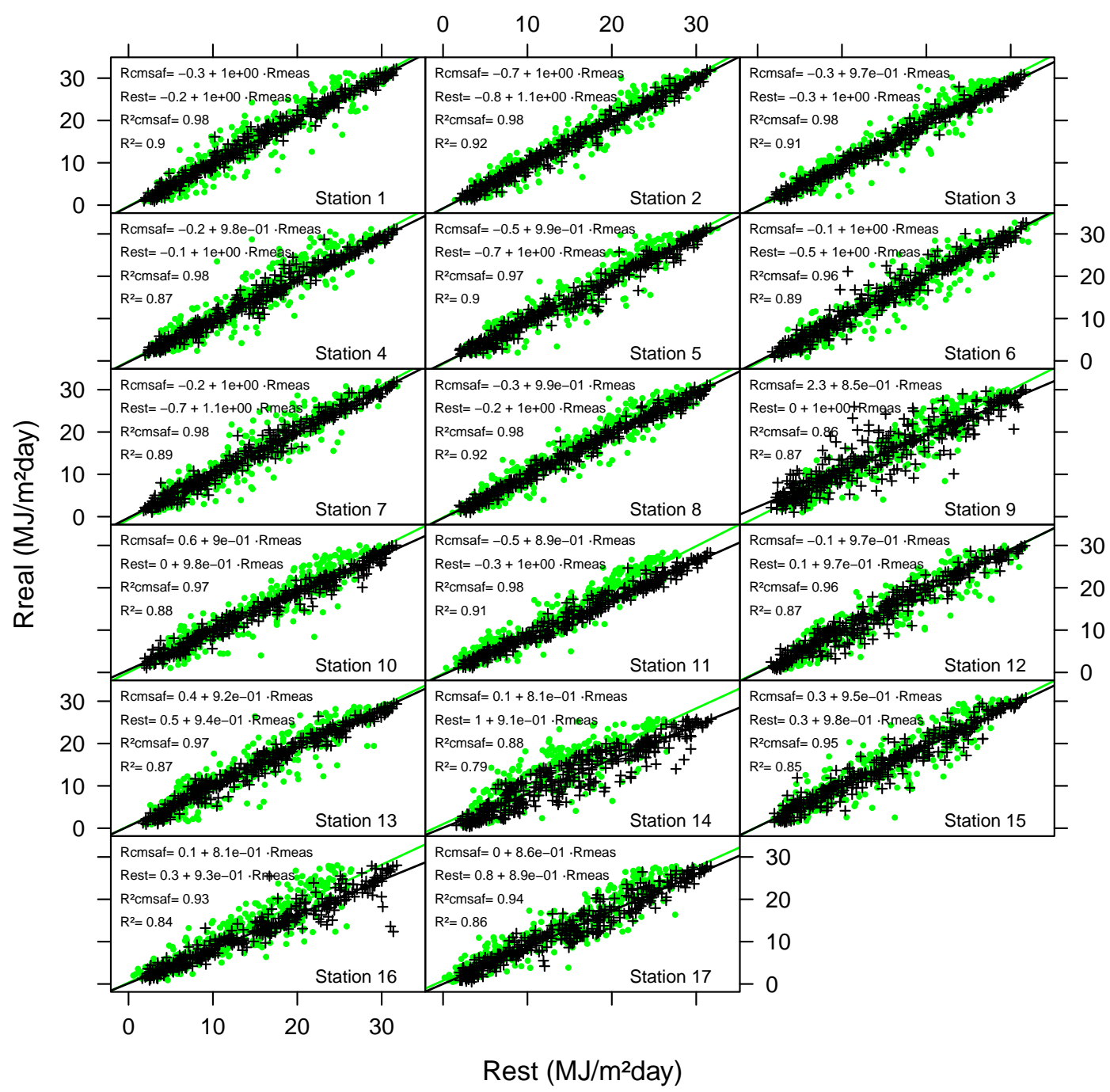

Figure 3: Correlation between $R_{s, \text { meas }}\left(\mathrm{MJ} / \mathrm{m}^{2}\right.$ day) and $R_{s, e s t}$ of the model proposed (model 24) with green points and $R_{s, \text { cmsaf }}$ with black crosses within the testing time series at all seventeen stations 

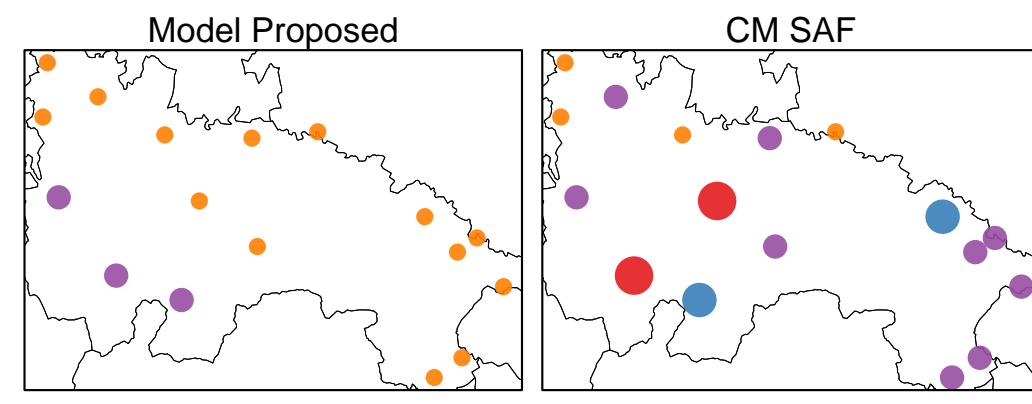

$8 \begin{aligned} & {[-22.95,-17.79]} \\ & -17.79,-12.63] \\ & -12.63,-7.463] \\ & -7.463,-2.3] \\ & -2.3,2.862]\end{aligned}$

Figure 4: Annual relative difference (\%) between $R_{s, m e a s}$ and $R_{s, e s t}$ for the model proposed (model 24) and CM SAF during the testing period (year 2011). 


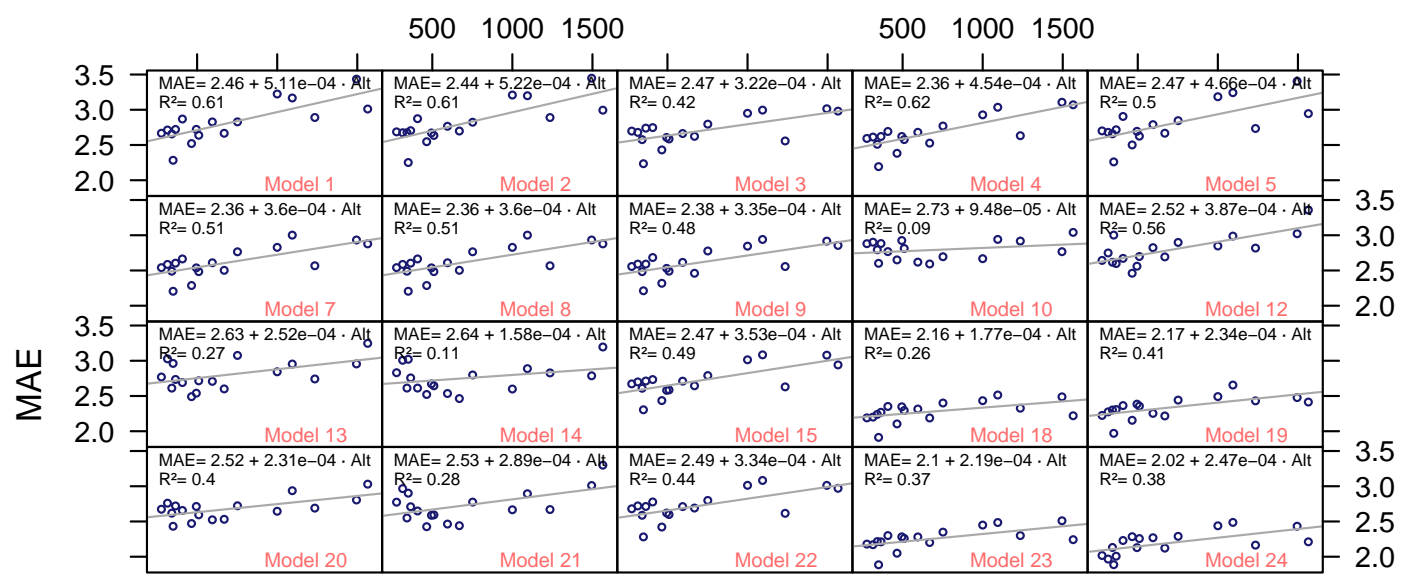

\section{Elevation}

Figure 5: Relation between elevation (m) and median of the $M A E_{\text {val }}\left(\mathrm{MJ} / \mathrm{m}^{2}\right.$ day). Models 11, 16 and 17 are not shown due to their high $M A E_{\text {val }}$ 


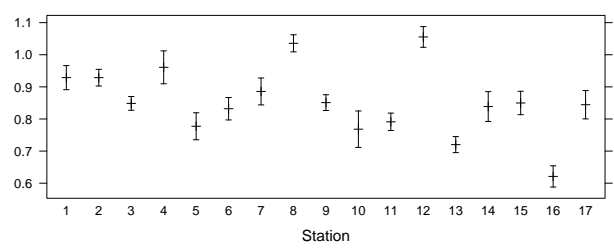

(a) Parameter a

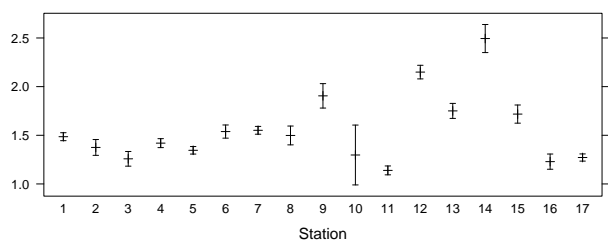

(c) Parameter c

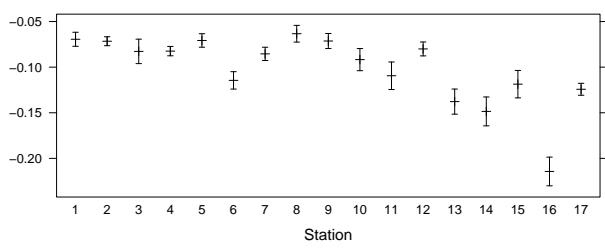

(e) Parameter e

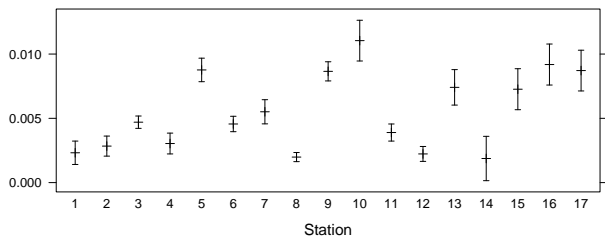

(g) Parameter g

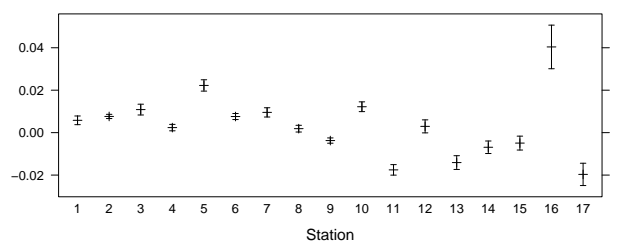

(i) Parameter 1

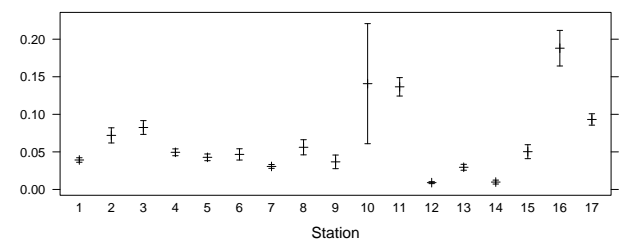

(b) Parameter b

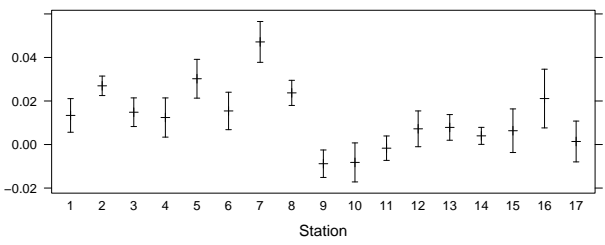

(d) Parameter d

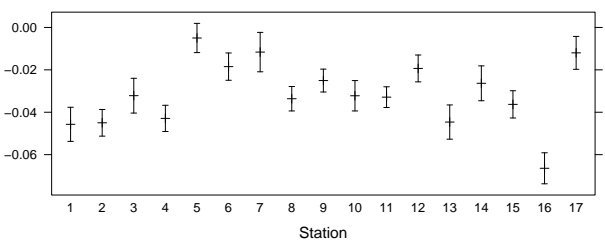

(f) Parameter $\mathrm{f}$

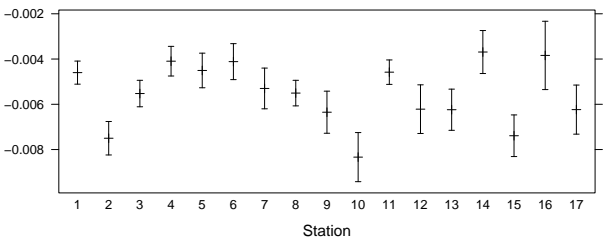

(h) Parameter h

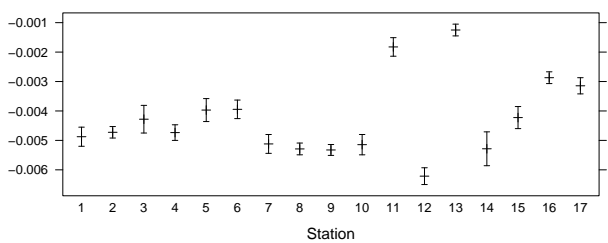

(j) Parameter m

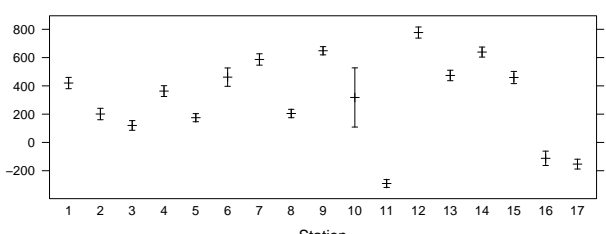

25

(k) Parameter $n$

Figure 6: Confidence intervals (95\% C.I., $\mathrm{n}=100)$ and median of the parameters of the proposed model (model 24) 


\begin{tabular}{rrrrr}
\hline Station & $M A E_{t e s, 24}$ & $M A E_{t e s, C M S A F}$ & $R M S E_{t e s, 24}$ & $R M S E_{t e s, C M S A F}$ \\
\hline 1 & 2.18 & 0.91 & 2.85 & 1.20 \\
2 & 1.92 & 0.86 & 2.46 & 1.17 \\
3 & 1.95 & 1.05 & 2.55 & 1.33 \\
4 & 2.22 & 1.09 & 3.00 & 1.43 \\
5 & 1.99 & 1.12 & 2.65 & 1.60 \\
6 & 2.16 & 1.13 & 2.83 & 1.67 \\
7 & 2.16 & 0.95 & 2.89 & 1.29 \\
8 & 1.93 & 0.93 & 2.45 & 1.19 \\
9 & 2.12 & 2.27 & 2.79 & 3.20 \\
10 & 2.03 & 1.37 & 2.71 & 1.80 \\
11 & 1.74 & 2.35 & 2.28 & 2.74 \\
12 & 2.32 & 1.34 & 2.99 & 1.79 \\
13 & 2.15 & 1.30 & 2.93 & 1.65 \\
14 & 2.49 & 3.18 & 3.36 & 4.02 \\
15 & 2.28 & 1.32 & 3.07 & 1.87 \\
16 & 2.15 & 2.83 & 2.99 & 3.63 \\
17 & 2.18 & 2.28 & 2.90 & 2.91 \\
\hline
\end{tabular}

Table 6: Testing errors of model 24 and CM SAF (year 2011)

\begin{tabular}{cccc}
\hline$a_{\text {mean }}$ & $a_{s d}$ & $b_{\text {mean }}$ & $b_{s d}$ \\
0.61 & 0.05 & 0.09 & 0.04 \\
\hline
\end{tabular}

Table 7: Summary of CM SAF re-calibration as per Equation 9 


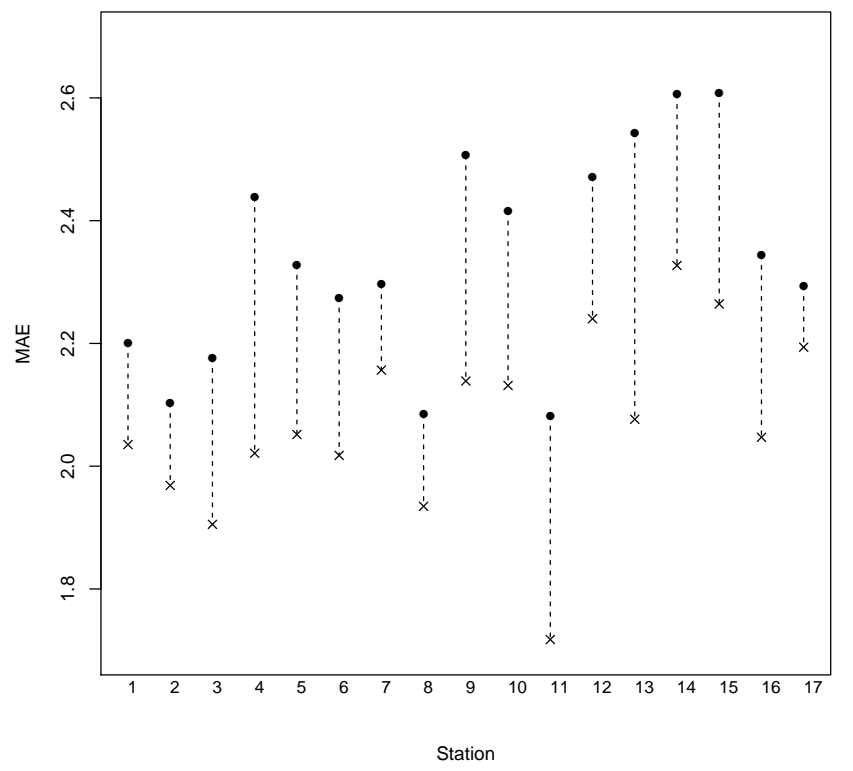

Figure 7: Average MAE (MJ $/ \mathrm{m}^{2}$ day) of the proposed model (model 24) for rainy days (black dots) and non-rainy days (black crosses) 